\title{
Highly pathogenic avian influenza virus of the A/H5N8 subtype, clade 2.3.4.4b, caused outbreaks in Kazakhstan in 2020
}

Asylulan Amirgazin ${ }^{1}$, Alexandr Shevtsov ${ }^{1}$, Talgat Karibayev ${ }^{2}$, Maxat Berdikulov ${ }^{2}$, Tamila Kozhakhmetova ${ }^{2}$, Laura Syzdykova ${ }^{1}$, Yerlan Ramankulov ${ }^{1,3}$, Alexandr Shustov ${ }^{\text {Corresp. } 1}$

1 National Center for Biotechnology, Nur-Sultan, Akmola region, Казахстан

2 National Reference Veterinary Center, Nur-Sultan, Akmola region, Казахстан

3 National Laboratory Astana, Nazarbayev University, Nur-Sultan, Akmola region, Казахстан

Corresponding Author: Alexandr Shustov

Email address: shustov@biocenter.kz

Background. Large poultry die-offs happened in Kazakhstan during autumn of 2020. The birds' disease appeared to be avian influenza. Northern Kazakhstan was hit first and then the disease propagated across the country affecting eleven provinces. This study reports the results of full-genome sequencing of viruses collected during the outbreaks and investigation of their relationship to avian influenza virus isolates in the contemporary circulation in Eurasia. Methods. Samples were collected from diseased birds during year-2020 outbreaks in Kazakhstan. Initial virus detection and subtyping was done using RT-PCR. Ten samples collected during expeditions to Northern and Southern Kazakhstan were used for full-genome sequencing of avian influenza viruses. Phylogenetic analysis was used to compare viruses from Kazakhstan to viral isolates from other world regions. Results. Phylogenetic trees for hemagglutinin and neuraminidase show that viruses from Kazakhstan belong to the A/H5N8 subtype and to the hemagglutinin H5 clade 2.3.4.4b. Deduced hemagglutinin amino acid sequences in all Kazakhstan's viruses in this study contain the polybasic cleavage site (KRRKR-G) indicative of the highly pathogenic phenotype. Building phylogenetic trees with the Bayesian phylogenetics results in higher statistical support for clusters than using distance methods. The Kazakhstan's viruses cluster with isolates from Southern Russia, Russian Caucasus, Ural region, South-Western Siberia. Other closely related prototypes are from Eastern Europe. The Central Asia Migratory Flyway passes over Kazakhstan and birds have intermediate stops in Northern Kazakhstan. It is postulated that the A/H5N8 subtype was introduced with migrating birds. Conclusion. The findings confirm the introduction of the highly pathogenic avian influenza viruses of the A/Goose/Guangdong/96 (Gs/GD) H5 lineage in Kazakhstan. This virus poses a tangible threat to public health. Considering the results of this study, it looks justifiable to 
undertake measures in preparation, such as install sentinel surveillance for human cases of avian influenza in the largest pulmonary units, develop a human A/H5N8 vaccine and human diagnostics capable of HPAI discrimination. 
1 Highly pathogenic avian influenza virus of the A/H5N8

2 subtype, clade 2.3.4.4b, caused outbreaks in

3 Kazakhstan in 2020

4

5

6

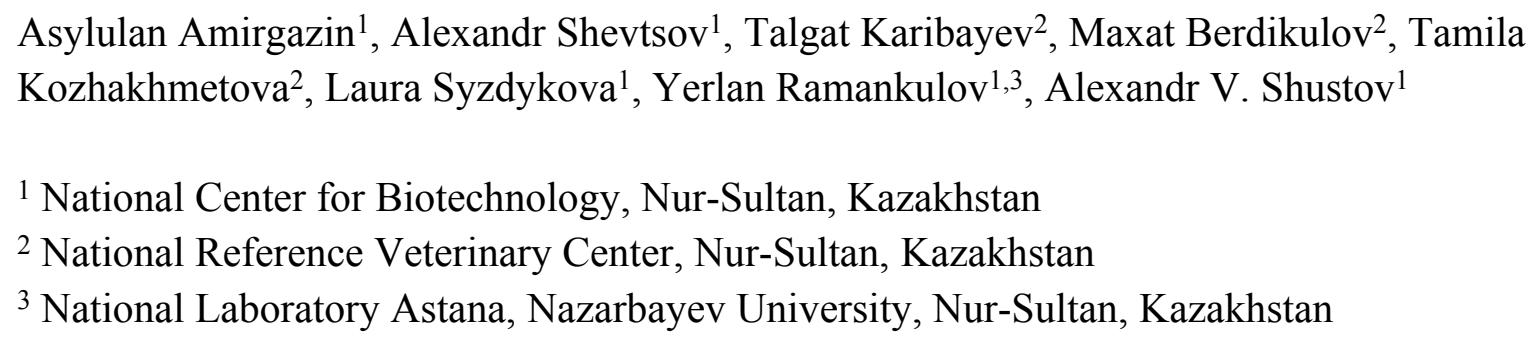

\section{Abstract}

Background. Large poultry die-offs happened in Kazakhstan during autumn of 2020. The birds' disease appeared to be avian influenza. Northern Kazakhstan was hit first and then the disease propagated across the country affecting eleven provinces. This study reports the results of fullgenome sequencing of viruses collected during the outbreaks and investigation of their relationship to avian influenza virus isolates in the contemporary circulation in Eurasia. Methods. Samples were collected from diseased birds during year-2020 outbreaks in Kazakhstan. Initial virus detection and subtyping was done using RT-PCR. Ten samples collected during expeditions to Northern and Southern Kazakhstan were used for full-genome sequencing of avian influenza viruses. Phylogenetic analysis was used to compare viruses from Kazakhstan to viral isolates from other world regions.

Results. Phylogenetic trees for hemagglutinin and neuraminidase show that viruses from Kazakhstan belong to the A/H5N8 subtype and to the hemagglutinin $\mathrm{H} 5$ clade 2.3.4.4b. Deduced hemagglutinin amino acid sequences in all Kazakhstan's viruses in this study contain the polybasic cleavage site (KRRKR-G) indicative of the highly pathogenic phenotype. Building phylogenetic trees with the Bayesian phylogenetics results in higher statistical support for clusters than using distance methods. The Kazakhstan's viruses cluster with isolates from Southern Russia, Russian Caucasus, Ural region, South-Western Siberia. Other closely related prototypes are from Eastern Europe. The Central Asia Migratory Flyway passes over Kazakhstan and birds have intermediate stops in Northern Kazakhstan. It is postulated that the A/H5N8 subtype was introduced with migrating birds. 
39 Conclusion. The findings confirm the introduction of the highly pathogenic avian influenza 40 viruses of the A/Goose/Guangdong/96 (Gs/GD) H5 lineage in Kazakhstan. This virus poses a 41 tangible threat to public health. Considering the results of this study, it looks justifiable to 42 undertake measures in preparation, such as install sentinel surveillance for human cases of avian 43 influenza in the largest pulmonary units, develop a human A/H5N8 vaccine and human 44 diagnostics capable of HPAI discrimination.

45

\section{Introduction}

47 Influenza viruses of type A are members in the genus Alphainfluenzavirus in the

48 Orthomyxoviridae family. Viruses in this species that can infect and productively circulate in 49 birds are called avian influenza viruses (AIVs). Naturally, aquatic birds and shorebirds, and more 50 specifically representatives from avian orders Anseriformes and Charadriiformes, are the natural 51 reservoir for AIVs [1,2]. AIVs can be highly contagious for gallinaceous birds including poultry (chicken, turkey). Variants dubbed highly pathogenic avian influenza viruses (HPAI) cause severe disease in gallinaceous birds sometimes resulting in massive birds' die-offs and devastating economic consequences for poultry farms [3]. Cross-species transmission from birds to mammals or humans is infrequent, however human infections with AIVs may be severe, with high casefatality rate [4]. The AIVs occasionally participate in the reassortment of genome segments. Reassortment between AIVs circulating in the same host-species is a recognized driver for the genetic diversity and evolution [5]. On the contrary, reassortment between viruses from different host classes, such as avian and mammalian viruses, is uncommon [6,7]. Importantly, rare events when a human virus acquired one or more gene segments from AIV resulted in pandemics $[8,9]$. Surveillance systems across the world share pervasive interest in the AIVs circulation and evolution. Surface proteins hemagglutinin (HA) and neuraminidase (NA) determine the antigenic properties of the virus. AIVs are divided into subtypes determined by the serological reactivity of hemagglutinin (18 HA subtypes) and neuraminidase (11 NA subtypes) [10]. Some AIVs cause rare but severe and life-threatening infections in humans, involving respiratory, gastrointestinal and neural systems [11]. A limited number of AIV subtypes seem to be capable of infecting humans, because until recently only certain combinations of avian HA (H5, H6, H7, H9 and H10) with NA (N1, N2, N3, N4, N6, N7, N8, N9), but excluding A/H5N8, have been reported in humans [12-17]. However, the subtype A/H5N8 was isolated from humans contacting poultry in 2020 [18]. A number of registered human A/H5N8 cases in that outbreak totaled to seven [19].

In Republic of Kazakhstan, starting from autumn 2020 there was a series of large outbreaks of a bird's disease that appeared to be avian influenza [20]. The first registered outbreaks occurred in settlements along the Kazakhstan-Russia border. To the year-end, the outbreaks have been registered in eleven country's provinces ('oblast'). Among them, provinces of Northern 
79 Kazakhstan were the most disease-affected regions. The state surveillance system for avian

80 influenza in Kazakhstan monitored the outbreaks. The veterinary service made efforts to slow

81 down disease propagation, set quarantines in affected settlements, imposed restrictions on the

82 export of poultry and poultry products, organized the prompt vaccination of remaining poultry.

83 In 2021, poultry outbreaks ceased, and as of the time this manuscript has been written the

84 country is declared AIV-free.

85 The goal of this study was to identify the closest relatives for the viruses that caused outbreaks in

86 Kazakhstan among contemporary isolates from other world regions, to confirm the existence of

87 the common circulation and postulate source(s) of introduction. Other goal was to describe

88 mutations in Kazakhstan's variants as compared to prototype isolates.

89

90 Materials \& Methods

91 Collecting samples for the study

92 The main reference laboratory in the Kazakhstan's state system for veterinary control and

93 surveillance, the National Reference Veterinary Center (NRVC), organized expeditions to

94 provinces in Northern and Southern Kazakhstan, where outbreaks of avian influenza were

95 officially registered. The NRVC veterinarians monitored areas within a $10 \mathrm{~km}$-radius from

96 poultry farms or disease-affected private households, as well as around settlements officially

97 designated as “disease reservoirs". Birds' carcasses or visibly diseased birds were examined. In

98 total, 2212 birds were examined and used for samples collection. Samples were brains, lungs,

99 trachea, spleen, intestinal tract and feces. The vast majority of the samples were from chickens,

100 domestic ducks and geese. Other samples were from mute swan (Cygnus olor), gray crow

101 (Corvus cornix), dove (Columba livia). Veterinarians diagnosed the disease in live birds based

102 on physical signs such as coma or prostration, unnatural position of head and neck, difficulty

103 breathing, refusal to feed, hyperemia and swelling of visible mucous membranes, flows from

104 beak and nasal openings, diarrhea. When examining carcasses, attention was paid to

105 hemorrhages in the mucous membranes, under serous membranes of internal organs, in the

106 subcutaneous tissue or in the muscles, the presence of enteritis, conjunctivitis or inflammation of

107 other internal organs, pulmonary edema.

108 Molecular diagnostics and virus subtyping

109 Frozen samples were transported to NRVC where PCR-diagnostics was performed. Pieces of

110 organs were homogenized using TissueLyser bead mill (Qiagen, Hilden, Germany) to produce

$11110 \%$ suspensions in saline $(0.9 \% \mathrm{NaCl})$. The suspensions were transferred in $1.5 \mathrm{ml}$ tubes and

112 centrifuged at 10,000 rpm for 30 seconds. The supernatants were used for RNA extraction.

113 Samples of feces were suspended to obtain 10\% suspensions in saline. The suspensions were

114 centrifuged and the supernatants were used for RNA extraction. Total RNA was purified using

115 QIAamp Viral RNA Kits (Cat\# 52906, Qiagen, Germany) as per the manufacturer's instructions.

116 Viral RNA was detected using a test-system for real-time PCR (RT-PCR), namely PCR-

117 INFLUENZA-A-FACTOR (Cat\# R10515-VET, LLC "VET FACTOR", Troitsk, Russia). This

118 test-system targets for amplification conserved (subtype-independent) sequences in the MP

Peer] reviewing PDF | (2021:09:66237:3:0:NEW 9 Feb 2022) 
119

120

121

122

123

124

125

126

127

128

129

130

131

132

133

134

135

136

137

138

139

140

141

142

143

144

145

146

147

148

149

150

151

152

153

154

155

156

157

segment in the viral genome. Another kit, PCR-FLU-TYPE-H5 / H7 / H9-FACTOR (Cat\# R12817-VET, LLC “VET FACTOR”, Troitsk, Russia) was used for HA typing. The kit allows assigning HA subtypes H5, H7, H9 based on results of one multiplexed reaction. Thermal cycler Rotor Gene 6000 was used to conduct the assay. Neuraminidase (NA) subtype was determined using sequencing and identification of the closest prototypes.

\section{Whole genome sequencing}

Ten samples collected by NRVC veterinarians during their visits to the most disease-affected settlements were selected for sequencing the full AIV genome. Larger utilization of the fullgenome sequencing was not possible due to the high costs. The samples were transferred to the National Center for Biotechnology (NCB). Reverse transcription was performed using SuperScript IV Reverse Transcriptase (Cat\# 18090010, Invitrogen, CA). The first strand-cDNA was primed using a universal primer MBTuni-12 (5'-ACGCGTGATCAGCAAAAGCAGG-3'). Eight segments in the AIV genome were PCR-amplified using a pair of MBTuni-12 and MBTuni-13 (5'-ACGCGTGATCAGTAGAAACAAGG-3') [21]. These primers target conserved sequences at the 5'- and 3'-termini of genomic segments. The high-fidelity DNA polymerase Phusion (Cat\# F-530XL, Invitrogen, CA) was used in PCR. Amplification products were purified using AMPure magnetic particles (Cat\# A63880, Beckman Coulter, USA) according to the manufacturer's instructions.

A fragment library was prepared using Nextera DNA Flex Library Prep Kit (20015829, Illumina, USA). Then, the MiSeq Reagent Kit v3, 600 cycles (MS-102-3003, Illumina, USA) and MiSeq platform (Illumina) were used to conduct the sequencing.

In addition to ten samples sequenced by the authors of this work, six different samples from the year-2020-outbreaks were sequenced in foreign laboratories, namely the Animal and Plant Health Agency (APHA) (Addlestone, United Kingdom) and WHO National Influenza Centre (WHO NIC) in St. Petersburg (Russia). In order to increase the representation of viruses from Kazakhstan in the study, we downloaded the APHA- and WHO NIC-generated sequences from GISAID [22-24] and included in the analysis in this work. The contribution from the originating laboratories is acknowledged in the Supplementary Information.

\section{Bioinformatics and phylogenetic analysis}

Quality of sequencing reads was assessed using the FastQC v0.11.9 program [25]. Trimming to quality values Q30 was performed using the SeqTK v1.3-r117/Sickle suite [26]. The sequencing reads were assembled into contigs using the BWA tool [27]. The following reference sequences were used as guides during the assembly of contigs: isolate A/White-fronted Goose/AN/1-1512/2016 (Genbank entries: MH988775.1 for HA, MH989503.1 - NA); and isolate A/chicken/Omsk/0112/2020 (GISAID accessions: EPI1813342 - PB2, EPI1813343 - PB1, EPI1813341 - PA, EPI1813338 - NP, EPI1813340 - MP, EPI1813339 - NS). Consensus sequences were produced using FreeBayes [28] and BCFtools [29]. The complete genomes of Kazakhstan's viruses determined in our laboratory were deposited in GISAID. Our entries are listed in the Supplementary Information. 
158 Sequences of historic prototypes and isolates in contemporary circulation were downloaded from 159 GISAID, their listing with acknowledgements to originating laboratories is provided in the 160 Supplementary Information. In the presented phylogenetic trees, viruses are identified by the 161 GISAID isolate name (EPI_ISL) and accession numbers (EPI\#) for particular segments. The goal 162 of this study was to identify isolates in the global circulation which share the closest similarity to

163

164

165

166

167

168

169

170

171

172

173

174

175

176

177

178

179

180

181

182

183

184

185

186

187

188

189

190

191

192

193

194

195

196

197

viruses from the recent outbreaks in Kazakhstan, and hence, to point to a possible path of introduction. Accordingly, all available complete-genome sequences from Russia, Europe, China and Asia-Pacific collected between Jan. 2020 - Aug. 2021 (i.e., in the time frame overlapping the Kazakhstan's outbreaks) were used in the initial analysis. For Africa and Middle East, sequences deposited from 2018 to 2021 were used because of the shortage of recent (2020-2021) submissions from these regions. The phylogenetic trees were constructed using the Bayesian probabilistic inference with Markov Chain Monte Carlo (MCMC) sampling algorithms in MrBayes v.3.2.7a [30]. The initial analysis was performed with a number of evolutionary process models, i.e. the Jukes-Cantor (JC69) model, generalized time-reversible (GTR) model, and GTR with rate variation across sites $(G T R+G)$ with four rate categories. The initial analysis was done using chain length of 1,000,000. Models showing good convergence such as an estimated sample size (ESS) of at least 1000, potential scale reduction factor (PSRF) close to one $(\mathrm{PSRF}=1)$, and also computation times $<24$ hours, were used in the further analysis.

Phylogenetic trees and support statistics for the branches presented in the paper and Supplementary Information were constructed using the MCMC chain length of $10,000,000$. With the final settings, ESS values were universally above 10,000 and PSRF $=1$ indicating perfect convergence. Consensus trees (50\% majority rule trees) are presented in the paper and the Supplementary Information. Posterior probability percents are shown near the nodes to indicate the statistical support for clustering. The H5 HA clades naming and labeling HA tree-branches as the clades 2.3.4.4a-2.3.4.4h are in accordance to the recent nomenclature [31].

FluSurver [32] was used to identify mutations in the influenza virus surface proteins which possibly influence biological characteristics such as host specificity, drugs resistance, virulence, etc.

\section{Results}

\section{Bird flu in Northern Kazakhstan, 2020}

During autumn 2020, unusually high numbers of wild birds' carcasses and also live but dying birds were noticed in many places in provinces of Northern Kazakhstan. Local veterinarians reported that initial die-offs started in wild wetland birds which had been migrating southwards.

However, exact losses to wild birds' populations are unknown because no attempts were made to quantify diseased or dead birds in wild habitats. Soon, die-offs in poultry began and attracted attention of national media and officials. Affected poultry were chickens, ducks, geese and turkeys. First officially registered outbreaks in poultry are dated in September 2020. The situation with the disease deteriorated during autumn of 2020, because the disease propagated across the country and increasing numbers of farms faced poultry die-offs. According to data in

Peer) reviewing PDF | (2021:09:66237:3:0:NEW 9 Feb 2022) 
198

199

200

201

202

203

204

205

206

207

208

209

210

211

212

213

214

215

216

217

218

219

220

221

222

223

224

225

226

227

228

229

230

231

232

233

234

235

236

237

the official NRVC report, the headcount of diseased birds in private households and commercial farms totaled 69,828 [33]. Destruction of all poultry in affected farms was mandatory. The total loss of poultry was 2 million at the end of 2020 including the culling [34]. Many farms stopped production for about 3 months resulting in an increase in market prices for poultry products [35]. Eleven out of fourteen Kazakhstan provinces had reported outbreaks before the country was declared avian flu-free. Four provinces of Northern Kazakhstan (Akmola, Kostanay, Pavlodar, North-Kazakhstan) had the largest numbers of outbreaks.

The state surveillance system for avian influenza collected samples from 2212 bird's carcasses. All the samples were tested for AIV using a commercial RT-PCR test system. Total number of PCR-positives amounted to 1976. Ten samples were taken from bird carcasses with overt pathological signs compatible with avian influenza. The samples were collected by NRVC specialists during on-site visits during different expeditions to North Kazakhstan and the Almaty province (Southern Kazakhstan). Map in Fig. 1 shows sampling locations. The ten samples were utilized for full-genome sequencing of Kazakhstan's AIVs.

\section{Molecular variability of surface glycoproteins}

Surface glycoproteins determine antigenic properties of the virus and undergo driving selection under the pressure of the host immune response. Comparing the HA nucleotide sequences within the group of Kazakhstan's viruses identifies 32 variable positions (per 1704 sequenced positions). Similar comparison of the NA nucleotide sequences shows 36 polymorphic positions (per $1413 \mathrm{nt}$ length). The majority of the nucleotide mutations are silent, as only four polymorphic sites were found at the amino acid level in HA, and 12 polymorphic sites were found in deduced NA amino acid sequences. Data on the amino acid mutations found in surface glycoproteins of Kazakhstan's viruses are presented in Tables 1-2 for HA, and Table 3-4 for NA. The deduced HA amino acid sequences contain the same cluster of basic amino acid residues (KRRKR-G) in all Kazakhstan viruses. This is the cleavage site separating two HA subunits (HA1 and HA2). The presence of such "polybasic cleavage site" is considered to be a major virulence determinant and associated with the HPAI phenotype [36].

The FluSurver service developed by the A*STAR Bioinformatics Institute in Singapore is a tool allowing identifying and annotating mutations in influenza virus proteins which may change virus' properties such as host range, drug resistance, etc. As compared to the nearest (FluSurverproposed) reference strain A/Sichuan/26221/2014(H5N6), the HA glycoproteins in Kazakhstan's viruses share common mutations: K3N, G16S, N110S, T139P, T156A, Q185R, V194I, A201E, N252D, E284G, M285V, I298V, K492E, V538A, I547M and V548M. In addition to the common mutations, two viruses (A/goose/Kazakhstan/4-190-20-B-H5N8-1/2020 and A/chicken/Kazakhstan/220-B-2-H5N8-4/2020) have S12G.

The NA sequences were screened for the presence of biologically relevant mutations using the service FluSurver. As compared to the nearest service-identified prototype A/Baikal teal/Korea Donglim/3/2014(H5N8), Kazakhstan's viruses share common mutations V8A, V27L, T32M, N46K, V49I, T81A, V106I, S136A, A190T, V201I, V213I, A245S, G263D, R264Q, T265A, T295M, I303V, T329A, V359M, S397L, Y450H, and K469G. Mutations V71I, E72K, N84S, 
238 P88S, Q330R, K469E are present in a small fraction (10-20\%) of our collection. Also, 40\% of 239 our viruses have K141R.

240 Relation of Kazakhstan's viruses to isolates in contemporary circulation

241 The main goal of phylogenetic analysis in this work was to identify isolates in the contemporary 242 circulation which are the closest relatives to Kazakhstan's viruses. In preliminary experiments

243 we compared different approaches for building phylogenetic trees and calculating the statistical 244 support for branches. The Maximum Likelihood (ML) method with the Bayesian probabilistic

245 selection of the best model-fitting phylogenies, produced the trees with more robust clustering as 246 compared to simple distance-based methods (Minimum Evolution (ME), etc.). Statistical support

247 values for branches in Bayesian-MCMC-phylogenetic trees are the posterior probabilities, and 248 these universally have been higher than bootstrap values commonly used with distance methods. 249 This justifies the use of the Bayesian MCMC approach. The trees presented in Fig. 2, Fig. 3 and 250 figures in the Supplementary Information have been produced using the Bayesian MCMC 251 modeling.

252 Phylogenetic trees for the segments HA and NA show that all sixteen viruses from Kazakhstan 253 belong to the A/H5N8 subtype. The HA H5 clade 2.3.4.4b comprises all viruses from

254 Kazakhstan (Fig. 2). The H5 clade 2.3.4.4b had evolved at around 2016 and currently this clade 255 predominates worldwide [37-51].

256 In phylogenetic trees (Fig. 2, Fig. 3 and the Supplementary Information) Kazakhstan's viruses 257 cluster with isolates from Southern Russia (e.g., Rostov-on-Don, Krasnodar), Russian Caucasus 258 (North Ossetia-Alania), Ural region (Chelyabinsk), South-Western Siberia (Omsk). Other closely 259 related prototypes are from Eastern Europe.

260 In the HA tree, the representatives from Kazakhstan group into five clusters with high statistical 261 support. These clusters are provisionally labeled as branches 1-5 (B1-B5) in Fig. 2. The given 262 labeling is used hereafter to describe the findings. The posterior probability percents for branches 263 B1-B5 are quite high (99-100\%). Also, the branch B5 may be divided into lower-order clusters 264 and a single-tip branch. Some of the lower-order branches (labeled B5-1, B5-2, B5-3 in Fig. 2) also have high statistical support (100\%). With this regard, the clusterization of the NA

267 sequences follows a very similar pattern. More specifically, branches B1-B4 in the NA tree (Fig. 3) have high statistical support. The latter comprise the same representatives from Kazakhstan as the eponymous branches in the HA tree. Sequences from the cluster B5 in the HA tree appear not to form a separate cluster in the NA tree. However, all studied NA sequences from Kazakhstan do form a mixed group with sequences from South-Western Siberia and Eastern Europe, and this 271 group has significant statistical support (73\%).

272 Some of the clusters defined in the HA and NA trees are actually present in phylogenetic trees

273 for all eight segments. The Kazakhstan's representatives in the branches B2, B4, B5-2, B5-3

274 show the same pattern of clusterization in phylogenetic trees for the segments MP, NP, NS, PA,

275 PB1 and PB2 (these trees are presented in the Supplementary Information).

276 Whereas the described relationships between the HPAI A/H5N8 viruses from Kazakhstan,

277 Siberia and Europe was easy to discern, it has been difficult to discover epidemiological 
278 correlates for molecular data such as the dependence between phylogenetic clustering and

279 sampling locations, timing, host species or case pathology. For example, the branches B1 and B2

280 both comprise viruses from the North and South of Kazakhstan. The branches B3, B4, B5-3

281 represent viruses from samples collected only in the North, and B4 (the largest cluster of

282 Kazakhstan's viruses) represents closely related sequences in all trees. In contrast to B5-3, the

283 branch B5-2 members are from the South. Finally, one "stray" variant in the single-tip branch

284 B5-1 is actually from Central Kazakhstan (this sample was sequenced in the APHA laboratory).

285 Nevertheless, the presented data confirm that the HPAI viruses in the circulation involving the

286 territory of Kazakhstan are genetically diverse. The current knowledge on the epidemiological

287 correlates for the Kazakhstan's HPAI viruses suffers from the real scarcity of both molecular and

288 observational data, and the way to establish such correlations is to enhance the surveillance.

289

290 Discussion

291 This study purpose was to determine HPAI A/H5N8 isolates in the global contemporary

292 circulation which show the closest relation to the viruses that caused the year-2020 outbreaks in

293 Kazakhstan. The results reveal that the most probable route of introduction is with migratory

294 birds.

295 The relation of Kazakhstan's viruses to isolates in the contemporary circulation shows that the

296 Kazakhstan's viruses cluster with isolates from bordering regions of Russia. That is in full

297 agreement with the epidemiological observations that the outbreaks were first registered in the

298 border regions. The A/H5N8 subtype is thought to have been introduced in Kazakhstan with

299 migratory birds, highlighting the importance of continuing and strengthening the efforts to

300 monitor influenza in migratory birds.

301 Viruses from Kazakhstan are grouped into several clusters with high statistical support. The

302 majority of the clusters present in the HA tree, are also present in trees for all other genomic

303 segments. Such grouping of the Kazakhstan's viruses suggests that the same studied outbreaks

304 actually were a result of a simultaneous introduction of genetically distinct ancestral lines. The

305 similarity in the grouping for different genomic segments provides an additional level of support

306 for the described phylogenetic relationships found in this study.

307 The HPAI A/H5N8 viruses appear to fit for efficient conquering of new territories. To the

308 authors' knowledge, this study is the first report describing the emergence of the

309 A/Goose/Guangdong/96 (Gs/GD) H5 lineage in Kazakhstan.

310 Kazakhstan is a large country (2,725,000 sq.km, that is $61 \%$ of a size of the European Union),

311 occupying the center of Eurasian continent and being a crossroad on ways from Eastern Europe

312 to China in one direction, and from European Russia - Urals- Western Siberia to Central Asia in

313 a cross direction. Whereas some parts of Kazakhstan are arid and deserted, Northern Kazakhstan

314 is rich in lakes. In fact, a group of large lakes called Tengis - Korgalzhyn (in the national park,

315 Korgalzhyn State Nature Reserve) have been included in the Ramsar list of wetlands of

316 international importance. Wetland birds there are numerous and diverse as represented by 112 
317 species, which constitute $87 \%$ of the Kazakhstan wetland avifauna. Lakes of Northern

318 Kazakhstan are important stopping points on birds' migratory routes.

319 The Northern Kazakhstan natural conditions with birds crowding during mass migrations enable 320 a rapid propagation of avian viruses. Transient coexistence in the same place of birds coming 321 from distant habitats, and of different species, can result in mixed infections with different AIV 322 strains and the reassortment of genome segments. By this way, a novel virus can evolve and 323 further propagate along the migration routes.

324 The state veterinary surveillance system for HPAI is in effect in Kazakhstan. The routine 325 surveillance exploits local veterinarians in settlements and administrative centers, and a central 326 reference laboratory (NRVC) located in the capitol. Local veterinarians are obliged to monitor 327 territories within a $10 \mathrm{~km}$-radius from poultry farms and collect samples from dead birds. Also, 328 veterinarians respond to appeals from households and farms in case of poultry die-offs, all 329 outbreaks are registered. The collected samples are transported to NRVC for laboratory testing. 330 The central laboratory reports HPAI outbreaks to the World Organization for Animal Health 331 (WOAH).

332 However, among the most important conclusions from this study is that the surveillance system 333 currently in place is unable to establish more detailed deterministic or statistical ties between the

334 335 336 337 338 339 molecular diversity of HPAI viruses in Kazakhstan and their epidemiological/biological characteristics relevant for predicting the situation development and calculating risks. This is because of several reasons, of which worth special mentioning is the bias towards sampling domestic and industrial flocks whereas wild birds' populations remain understudied; low rates of producing molecular data; the lack of studies of the phenotype of HPAI isolates on laboratory infection models. The latter studies are planned at the NCB.

The AIV subtype A/H5N8 was initially detected in 2010, then it caused major birds die-offs in South Korea in 2014, and since then its wide circulation has been described in the Northern Hemisphere including countries of Asia, Europe and North America [52-57]. However, until the outbreaks of 2020, the A/H5N8 subtype has not been found in Kazakhstan. In the Northern Kazakhstan's neighbor country Russia, A/H5N8 HPAI circulation has been recorded since 2014, however the early report described isolating of this subtype only in Russia's East, relatively far from Kazakhstan [58]. The recent propagation of A/H5N8 HPAI across Eurasia was widely covered in public media, however scientific reports with the molecular characterization of Kazakhstan viruses are scarce [48]. The phylogenetic relationship found in this study between the viruses from Kazakhstan and Russia is expected. Russian Caspian, Russian Caucasus, Southern Ural and South-Western Siberia - all are Kazakhstan's neighbors. In fact, the border between Kazakhstan and Russia is the longest continuous land border in the world $(7591 \mathrm{~km})$. The whole Kazakhstan's territory lies under the Central Asia Migratory Flyway (also dubbed as Central Asian-Indian Flyway). This flyway connects breeding grounds along the Russian Arctic Ocean coast with overwintering places in the Indian subcontinent [59]. The outbreak began in early autumn contemporary with the beginning of birds' seasonal migration. An assumption that birds migrating from the north introduced the virus into Kazakhstan is supported by the fact that 
357 the Russian regions of Chelyabinsk (at Urals) and Omsk (at Western Siberia) had declared bird 358 flu quarantines on August 3 and September 5, respectively, i.e. before the disease came overt in 359 Kazakhstan [60].

360 With regard to mutations present in the HA protein, two rare mutations N110S and T139P reside 361 in positions that were shown to make contacts with terminal sialic acids present on sugar chains

362 of cell surface glycans. Thus these mutations affect the receptor recognition and may be involved 363 in a host specificity shift. With this regard there are experimental data confirming that mutations 364 of the sialic acid-contacting residues promote the host switch. One HA mutation in an A/H5N1 365 virus in a position homologous to N110S enhanced binding of the avian virus to a human-type 366 receptor [61]. A role in shifting the viral host tropism to the human host was confirmed for the 367 mutation T139P [62].

368 Three mutations in NA (N46K, N84S and T295M) deserve special mentioning because these 369 mutations remove predicted $\mathrm{N}$-linked glycosylation sites and thus are assumed to diminish 370 glycosylation in the NA stem region. There are experimental studies showing that the abrogation 371 of the NA glycosylation enhances the virulence, increases pathology in birds and mice $[63,64]$.

372 However, additional experimentation would be needed to determine if the same outcomes would 373 be observed for the Kazakhstan's A/H5N8 viruses. The whole genetic backbone of the virus 374 including internal gene segments plays a role in whether a biological outcome will be achieved. 375 Indeed, further in vitro studies are planned to produce strains of Kazakhstan's AIVs, confirm the 376 HPAI phenotype and study the virulence.

377 Being a source of economic pain for poultry producers and a threat to public health, the Gs/GD378 lineage HPAI viruses is a problem worth of international attention [42]. The A/H5N8 subtype is 379 pathogenic to small mammals $[58,65]$ and is able to infect people [19]. No human A/H5N8 cases 380 have been reported in Kazakhstan before the official end of the outbreaks. As of the time this 381 paper is prepared, Kazakhstan is officially declared to be AIV-free.

382

383 
384

385

386

387

388

389

390

391

392

393

394

395

396

397

398

399

400

401

402

403

404

405

406

407

408

409

410

411

412

413

414

415

416

417

418

419

420

421

422

423

424

\section{Conclusions}

The findings confirm that the A/H5N8 subtype continues its conquering epidemiological history in Central Eurasia. The surveillance and healthcare must be prepared.

\section{Acknowledgements}

The authors acknowledge the contribution from the originating laboratories which submitted data to the GISAID database. A list of the originating laboratories for the sequences that used in this study is presented in the Supplementary Information.

\section{Funding}

This research was funded by the Science Committee of the Ministry of Education and Science of the Republic of Kazakhstan (Grant No. AP09562122).

\section{Conflicts of Interest / Competing Interests}

All authors declare that no competing interests exist.

\section{Data Availability}

The data used to prepare this study are presented in the paper, and in the Supplementary Information. Accession numbers for sequences uploaded in the GISAID database are available in the Supplementary Information.

\section{References}

1. Olsen B, Munster VJ, Wallensten A, Waldenström J, Osterhaus AD, Fouchier RA (2006) Global patterns of influenza a virus in wild birds. Science 312(5772):384-8. https://doi.org/10.1126/science.1122438

2. Venkatesh D, Poen MJ, Bestebroer TM et.al (2018) Avian Influenza Viruses in Wild Birds: Virus Evolution in a Multihost Ecosystem. J Virol 92(15):00433. https://doi.org/10.1128/JVI.00433-18

3. Alexander DJ (2000) A review of avian influenza in different bird species. Vet Microbiol 74(1-2):3-13. https://doi.org/10.1016/S0378-1135(00)00160-7

4. Peiris JS, de Jong MD, Guan Y (2007) Avian influenza virus (H5N1): a threat to human health. Clin Microbiol Rev 20(2):243-67. https://doi.org/10.1128/CMR.00037-06

5. Postnikova Y, Treshchalina A, Boravleva E et. al (2021) Diversity and Reassortment Rate of Influenza A Viruses in Wild Ducks and Gulls. Viruses 13(6): 1010. https://doi.org/10.3390/v13061010

6. Ganti K, Bagga A, DaSilva J et.al (2021) Avian Influenza A Viruses Reassort and Diversify Differently in Mallards and Mammals. Viruses 13(3):509. https://doi.org/10.3390/v13030509

7. Schrauwen EJ, Bestebroer TM, Rimmelzwaan GF et. al (2013) Reassortment between Avian $\mathrm{H} 5 \mathrm{~N} 1$ and human influenza viruses is mainly restricted to the matrix and 
442

443

444

445

446

447

448

449

450

451

452

453

454

455

456

457

458

459

460

461

462

463

464

465

466

467

468

469

470

471

neuraminidase gene segments. PLoS One 8(3):e59889. https://doi.org/10.1371/journal.pone.0059889

8. Schrauwen EJ, Fouchier RA (2014) Host adaptation and transmission of influenza A viruses in mammals. Emerg Microbes Infect 3(2):e9. https://dx.doi.org/10.1038\%2Femi.2014.9

9. Webster RG, Bean WJ, Gorman OT et.al (1992) Evolution and ecology of influenza A viruses. Microbiol Rev 56(1):152-79. https://doi.org/10.1128/mr.56.1.152-179.1992

10. Kosik I, Yewdell JW (2019) Influenza Hemagglutinin and Neuraminidase: Yin ${ }^{-}$Yang Proteins Coevolving to Thwart Immunity. Viruses 11(4): 346. https://doi.org/10.3390/v11040346

11. Wong SS, Yuen KY (2006) Avian influenza virus infections in humans. Chest № 129(1):156-68. https://doi.org/10.1378/chest.129.1.156

12. Mostafa A, Abdelwhab EM, Mettenleiter TC, Pleschka S (2018) Zoonotic Potential of Influenza A Viruses: A Comprehensive Overview. Viruses № 10(9): 497. https://doi.org/10.3390/v10090497

13. Fouchier RA, Schneeberger PM, Rozendaal FW et.al (2004) Avian influenza A virus (H7N7) associated with human conjunctivitis and a fatal case of acute respiratory distress syndrome. Proc Natl Acad Sci USA № 101(5):1356-61. https://doi.org/10.1073/pnas.0308352100

14. Lin YP, Shaw M, Gregory V et. al (2000) Avian-to-human transmission of H9N2 subtype influenza A viruses: relationship between H9N2 and H5N1 human isolates. Proc Natl Acad Sci USA № 97(17):9654-8. https://doi.org/10.1073/pnas.160270697

15. Munster VJ, de Wit E, van Riel D et.al (2007) The molecular basis of the pathogenicity of the Dutch highly pathogenic human influenza A H7N7 viruses. J Infect Dis № 196(2):258-65. https://doi.org/10.1086/518792

16. Peiris M, Yuen KY, Leung CW et.al (1999) Human infection with influenza H9N2. Lancet № 354(9182):916-7. https://doi.org/10.1016/s0140-6736(99)03311-5

17. Abdel-Ghafar AN, Chotpitayasunondh T, Gao Z et.al (2008) Update on avian influenza A (H5N1) virus infection in humans. $N$ Engl J Med № 358(3):261-73. https://doi.org/10.1056/nejmra0707279

18. Pyankova OG, Susloparov IM, Moiseeva AA et.al (2021) Isolation of clade 2.3.4.4b $\mathrm{A}(\mathrm{H} 5 \mathrm{~N} 8)$, a highly pathogenic avian influenza virus, from a worker during an outbreak on a poultry farm, Russia, December 2020. Euro Surveill № 26(24). https://doi.org/10.2807/1560-7917.es.2021.26.24.2100439

19. WH (2021) Avian influenza A(H5N8) infects humans in Russian Federation. https://www.euro.who.int/en/countries/kazakhstan/news/news/2021/3/avian-influenzaah5n8-infects-humans-in-russian-federation

20. Kazakhstan S. Avian influenza in Kazakhstan: about 2 million birds died in 2020 . https://ru.sputnik.kz/economy/20210106/15935875/ptichiy-gripp-v-kazakhstan-okolo-2millionov-ptits-pogiblo-v-2020-godu.html 2021.

21. Zhou B, Donnelly ME, Scholes DT et. al (2009) Single-reaction genomic amplification accelerates sequencing and vaccine production for classical and Swine origin human influenza a viruses. J Virol № 83(19):10309-3. https://doi.org/10.1128/jvi.01109-09

22. GISAID Enabling rapid and open access to epidemic and pandemic virus data. https://www.gisaid.org/

23. Elbe S, Buckland-Merrett G (2017) Data, disease and diplomacy: GISAID's innovative contribution to global health. Glob Chall 1(1):33-46. https://doi.org/10.1002/gch2.1018

Peer) reviewing PDF | (2021:09:66237:3:0:NEW 9 Feb 2022) 
472

473

474

475

476

477

478

479

480

481

482

483

484

485

486

487

488

489

490

491

492

493

494

495

496

497

498

499

500

501

502

503

504

505

506

507

508

509

510

511

512

513

514

515

516

24. Shu Y, McCauley J (2017) GISAID: Global initiative on sharing all influenza data - from vision to reality. Euro Surveill 22(13). https://dx.doi.org/10.2807\%2F15607917.ES.2017.22.13.30494

25. Babraham Bioinformatics https://www.bioinformatics.babraham.ac.uk/projects/fastqc/

26. Shen W, Le S, Li Y, Hu F (2016) SeqKit: A Cross-Platform and Ultrafast Toolkit for FASTA/Q File Manipulation. PLoS One 11(10):e0163962. https://doi.org/10.1371/journal.pone.0163962

27. Li H, Durbin R (2010) Fast and accurate long-read alignment with Burrows-Wheeler transform. Bioinformatics 26(5):589-95. https://doi.org/10.1093/bioinformatics/btp698

28. GitHub FreeBayes ahvdUmagh. GitHub (2021) FreeBayes, a haplotype-based variant detector. User manual and guide. https://github.com/freebayes/freebayes

29. Danecek P, Bonfield JK, Liddle J et.al (2021) Twelve years of SAMtools and BCFtools. Gigascience 10(2):008. https://doi.org/10.1093/gigascience/giab008

30. Ronquist F, Teslenko M, van der Mark P et. al (2012) MrBayes 3.2: Efficient Bayesian phylogenetic inference and model choice across large model space. Syst.Biol 61(3):53942. https://doi.org/10.1093/sysbio/sys029

31. Antigenic and genetic characteristics of zoonotic influenza viruses and development of candidate vaccine viruses for pandemic preparedness. Wlky Epidemiol Rec. 95(44):52539. https://apps.who.int/iris/handle/10665/336259

32. FluSurver Real-time surveillance of influenza mutations. https://flusurver.bii.astar.edu.sg/

33. National Reference Veterinary Center, unpublished report. 2021. http://www.nrcv.kz/

34. Kazakhstan S. Avian influenza in Kazakhstan: about 2 million birds died in 2020. https://ru.sputnik.kz/economy/20210106/15935875/ptichiy-gripp-v-kazakhstan-okolo-2millionov-ptits-pogiblo-v-2020-godu.html 2021.

35. EurasiaNet (2020) Kazakhstan: Avian flu kills nearly 1 million poultry. https://eurasianet.org/kazakhstan-avian-flu-kills-nearly-1-million-poultry

36. Tscherne DM, García-Sastre A (2011) Virulence determinants of pandemic influenza viruses. J Clin Invest 121(1):6-13. https://dx.doi.org/10.1172\%2FJCI44947

37. Organization WH. Antigenic and genetic characteristics of zoonotic influenza viruses and development of candidate vaccine viruses for pandemic preparedness. Wkly Epidemiol Rec 93(12):142-152. https://apps.who.int/iris/handle/10665/272

38. Lee DH, Sharshov K, Swayne DE et.al (2017) Novel Reassortant Clade 2.3.4.4 Avian Influenza A(H5N8) Virus in Wild Aquatic Birds, Russia, 2016. Emerg Infect Dis 23(2):359-60. https://doi.org/10.3201/eid2302.161252

39. Lee DH, Bertran K, Kwon JH, Swayne DE (2017) Evolution, global spread, and pathogenicity of highly pathogenic avian influenza $\mathrm{H} 5 \mathrm{Nx}$ clade 2.3.4.4. J Vet Sci 18(S1):269-80. https://doi.org/10.4142/jvs.2017.18.s1.269

40. Chen P, Xie JF, Lin Q et. al (2019) A study of the relationship between human infection with avian influenza a (H5N6) and environmental avian influenza viruses in Fujian, $\begin{array}{llll}\text { China. BMC Infect } & \text { Dis }\end{array}$ https://bmcinfectdis.biomedcentral.com/articles/10.1186/s12879-019-4145-6

41. Le TH, Nguyen NT (2014) Evolutionary dynamics of highly pathogenic avian influenza A/H5N1 HA clades and vaccine implementation in Vietnam. Clin Exp Vaccine Res 3(2):117-27. https://dx.doi.org/10.7774\%2Fcevr.2014.3.2.117

PeerJ reviewing PDF | (2021:09:66237:3:0:NEW 9 Feb 2022) 
517

518

519

520

521

522

523

524

525

526

527

528

529

530

531

532

533

534

535

536

537

538

539

540

541

542

543

544

545

546

547

548

549

550

551

552

553

554

555

556

557

558

559

560

561

42. Yamaji R, Saad MD, Davis CT et. al (2020) Pandemic potential of highly pathogenic avian influenza clade 2.3.4.4 A(H5) viruses. Rev Med Virol 30(3):e2099. https://doi.org/10.1002/rmv.2099

43. Gu M, Zhao G, Zhao K et.al (2013) Novel variants of clade 2.3.4 highly pathogenic avian influenza A(H5N1) viruses, China. Emerg Infect Dis 19(12):2021-4. https://doi.org/10.3201/eid1912.130340

44. Tarek M, Naguib MM, Arafa AS et. al (2021) Epidemiology, Genetic Characterization, and Pathogenesis of Avian Influenza H5N8 Viruses Circulating in Northern and Southern Parts of Egypt, 2017-2019. Animals (Basel) 11(8). https://doi.org/10.3390/ani11082208

45. Zhang J, Chen Y, Shan N et.al (2020) Genetic diversity, phylogeography, and evolutionary dynamics of highly pathogenic avian influenza A (H5N6) viruses. Virus Evol 6(2):veaa079. https://doi.org/10.1093/ve/veaa079

46. Pohlmann A, Hoffmann D, Grund C et.al (2019) Genetic Characterization and Zoonotic Potential of Highly Pathogenic Avian Influenza Virus A(H5N6/H5N5), Germany, 20172018. Emerg Infect Dis 25(10):1973-6. https://doi.org/10.3201/eid2510.181931

47. Laleye AT, Bianco A, Shittu I et.al (2021) Genetic characterization of highly pathogenic avian Influenza $\mathrm{H} 5 \mathrm{Nx}$ clade $2.3 .4 .4 \mathrm{~b}$ reveals independent introductions in nigeria. Transbound Emerg Dis 2021. https://doi.org/10.1111/tbed.14000

48. Lewis NS, Banyard AC, Whittard E et.al (2021) Emergence and spread of novel H5N8, H5N5 and H5N1 clade 2.3.4.4 highly pathogenic avian influenza in 2020. Emerg Microbes Infect 10(1):148-51. https://dx.doi.org/10.1080\%2F22221751.2021.1872355

49. Globig A, Staubach C, Sauter-Louis C et.al (2017) Highly Pathogenic Avian Influenza H5N8 Clade 2.3.4.4b in Germany in 2016/2017. Front Vet Sci 4(240). https://doi.org/10.3389/fvets.2017.00240

50. Liang Y, Nissen JN, Krog JS et.al (2020) Novel Clade 2.3.4.4b Highly Pathogenic Avian Influenza A H5N8 and H5N5 Viruses in Denmark, 2020. Viruses 13(5):886. https://doi.org/10.3390/v13050886

51. Baek YG, Lee YN, Lee DH et.al (2021) Multiple Reassortants of H5N8 Clade 2.3.4.4b Highly Pathogenic Avian Influenza Viruses Detected in South Korea during the Winter of 2020-2021. Viruses 13(3):490. https://doi.org/10.3390/v13030490

52. Zhao K, Gu M, Zhong L et.al (2013) Characterization of three H5N5 and one H5N8 highly pathogenic avian influenza viruses in China. Vet Microbiol 163(3-4):351-7. https://doi.org/10.1016/j.vetmic.2012.12.025

53. Jeong J, Kang HM, Lee EK et. al (2014) Highly pathogenic avian influenza virus (H5N8) in domestic poultry and its relationship with migratory birds in South Korea during 2014. Vet Microbiol 173(3-4):249-57. https://doi.org/10.1016/j.vetmic.2014.08.002

54. Lee YJ, Kang HM, Lee EK et.al (2014) Novel reassortant influenza A(H5N8) viruses, South Korea, 2014. Emerg Infect Dis 20(6):1087-9. https://doi.org/10.3201/eid2006.140233

55. Bouwstra R, Heutink R, Bossers A et.al (2015) Full-Genome Sequence of Influenza A(H5N8) Virus in Poultry Linked to Sequences of Strains from Asia, the Netherlands, 2014. Emerg Infect Dis 21(5):872-4. https://doi.org/10.3201/eid2105.141839

56. Hanna A, Banks J, Marston DA et.al (2015) Genetic Characterization of Highly Pathogenic Avian Influenza (H5N8) Virus from Domestic Ducks, England, November 2014. Emerg Infect Dis 21(5):879-2. https://dx.doi.org/10.3201\%2Feid2105.141954

Peer) reviewing PDF | (2021:09:66237:3:0:NEW 9 Feb 2022) 
562

563

564

565

566

567

568

569

570

571

572

573

574

575

576

577

578

579

580

581

582

583

584

585

586

587

588

589

590

591
57. Pasick J, Berhane Y, Joseph T et.al (2015) Reassortant highly pathogenic influenza A H5N2 virus containing gene segments related to Eurasian H5N8 in British Columbia, Canada, 2014. Sci Rep 5(1):9484. http://dx.doi.org/10.1038/srep09484

58. Marchenko VY, Susloparov IM, Kolosova NP et.al (2015) Influenza A(H5N8) virus isolation in Russia, 2014. Arch Virol 160(11):2857-60. https://doi.org/10.1016/j.virol.2018.09.024

59. Si Y, Skidmore AK, Wang T et.al (2009) Spatio-temporal dynamics of global H5N1 outbreaks match bird migration patterns. Geospat Health 4(1):65-78. https://doi.org/10.4081/gh.2009.211

60. In the Russian region bordering the North Kazakhstan region, quarantine was announced due to bird flu. https://informburo.kz/novosti/v-prigranichnom-s-sko-rossiyskom-regioneobyavili-karantin-iz-za-ptichego-grippa.html

61. Su Y, Yang HY, Zhang BJ et.al (2008) Analysis of a point mutation in H5N1 avian influenza virus hemagglutinin in relation to virus entry into live mammalian cells. Arch Virol 153(12):2253-61. https://doi.org/10.1007/s00705-008-0255-y

62. Yamada S, Suzuki Y, Suzuki T et.al (2006) Haemagglutinin mutations responsible for the binding of H5N1 influenza A viruses to human-type receptors. Nature 444(7117):378-82. https://doi.org/10.1038/nature05264

63. Chen S, Quan K, Wang D et.al (2020) Truncation or Deglycosylation of the Neuraminidase Stalk Enhances the Pathogenicity of the H5N1 Subtype Avian Influenza Virus in Mallard Ducks. Front Microbiol 11:583588. https://doi.org/10.3389/fmicb.2020.583588

64. Park S, Il Kim J, Lee I et.al (2017) Adaptive mutations of neuraminidase stalk truncation and deglycosylation confer enhanced pathogenicity of influenza A viruses. Sci Rep 7(1):10928. https://doi.org/10.1038/s41598-017-11348-0

65. Marchenko VY, Susloparov IM, Komissarov AB et.al (2017) Reintroduction of highly pathogenic avian influenza $\mathrm{A} / \mathrm{H} 5 \mathrm{~N} 8$ virus of clade 2.3.4.4. in Russia. Arch Virol 162(5):1381-5. https://doi.org/10.1007/s00705-017-3246-Z 


\section{Table 1 (on next page)}

Occurrence of amino acid mutations in hemagglutinin in AIVs from Kazakhstan 


\begin{tabular}{|l|l|l|l|}
\hline Amino acid position & Polymorphism & \multicolumn{2}{|l|}{ Allelic frequencies (\%) } \\
\hline 12 & $\mathrm{~S} / \mathrm{G}$ & $\mathrm{S}(87.5)$ & $\mathrm{G}(12.5)$ \\
\hline 88 & $\mathrm{R} / \mathrm{K}$ & $\mathrm{R}(93.8)$ & $\mathrm{K}(6.3)$ \\
\hline 166 & $\mathrm{~L} / \mathrm{I}$ & $\mathrm{L}(93.8)$ & $\mathrm{I}(6.3)$ \\
\hline 205 & $\mathrm{~N} / \mathrm{T}$ & $\mathrm{N}(93.8)$ & $\mathrm{T}(6.3)$ \\
\hline
\end{tabular}

1 
Table 2 (on next page)

List of amino acid mutations found in hemagglutinin in AIVs from Kazakhstan 


\begin{tabular}{|c|c|c|c|c|}
\hline \multirow[t]{2}{*}{ Name, Accession } & \multicolumn{4}{|c|}{ Position } \\
\hline & 12 & 88 & 166 & 205 \\
\hline A/goose/Kazakhstan/4-190-20-B-H5N8-1/2020 EPI1882525 & G & $\mathrm{R}$ & $\mathrm{L}$ & $\mathrm{N}$ \\
\hline A/chicken/Kazakhstan/220-B-2-H5N8-4/2020 EPI1882547 & $\mathrm{G}$ & $\mathrm{R}$ & $\mathrm{L}$ & $\mathrm{N}$ \\
\hline A/duck/Kazakhstan/12-20-B-Talg-11/2020 EPI1882548 & $\mathrm{S}$ & $\mathrm{R}$ & $\mathrm{L}$ & $\mathrm{N}$ \\
\hline A/goose/Kazakhstan/7-20-B-Talg-12/2020 EPI1882551 & $\mathrm{S}$ & $\mathrm{R}$ & $\mathrm{L}$ & $\mathrm{N}$ \\
\hline A/swan/Kazakhstan/9-20-B-Talg-39/2020 EPI1882552 & $\mathrm{S}$ & $\mathrm{R}$ & $\mathrm{L}$ & $\mathrm{N}$ \\
\hline A/chicken/Kazakhstan/12-20-B-Talg-45/2020 EPI1882555 & $\mathrm{S}$ & $\mathrm{R}$ & $\mathrm{L}$ & $\mathrm{N}$ \\
\hline A/crow/Kazakhstan/15-20-B-Talg-4/2020 EPI1882556 & $\mathrm{S}$ & $\mathrm{R}$ & $\mathrm{L}$ & $\mathrm{N}$ \\
\hline A/swan/Kazakhstan/1-267-20-B-Talg-52/2020 EPI1882559 & $\mathrm{S}$ & $\mathrm{R}$ & $\mathrm{L}$ & $\mathrm{N}$ \\
\hline A/pigeon/Kazakhstan/15-20-B-Talg-5/2020 EPI1882560 & $\mathrm{S}$ & $\mathrm{R}$ & $\mathrm{L}$ & $\mathrm{N}$ \\
\hline A/chicken/Kazakhstan/1-20-B-Talg-67/2020 EPI1882563 & $\mathrm{S}$ & $\mathrm{R}$ & $\mathrm{L}$ & $\mathrm{N}$ \\
\hline A/domestic goose/Kazakhstan/1-248_2-20-B/2020 EPI1811601 & $\mathrm{S}$ & $\mathrm{R}$ & $\mathrm{I}$ & $\mathrm{T}$ \\
\hline A/chicken/Kazakhstan/Kn-3/2020 EPI1839261 & $\mathrm{S}$ & $\mathrm{R}$ & $\mathrm{L}$ & $\mathrm{N}$ \\
\hline A/chicken/Kazakhstan/Kn-6/2020 EPI1839269 & $\mathrm{S}$ & $\mathrm{R}$ & $\mathrm{L}$ & $\mathrm{N}$ \\
\hline A/domestic duck/Kazakhstan/1-274-20-B/2020 EPI1811611 & $\mathrm{S}$ & $\mathrm{K}$ & $\mathrm{L}$ & $\mathrm{N}$ \\
\hline A/domestic goose/Kazakhstan/1-242_2-20-B/2020 EPI1811619 & $\mathrm{S}$ & $\mathrm{R}$ & $\mathrm{L}$ & $\mathrm{N}$ \\
\hline A/mute swan/Kazakhstan/1-267-20-B/2020 EPI1811584 & $\mathrm{S}$ & $\mathrm{R}$ & $\mathrm{L}$ & $\mathrm{N}$ \\
\hline
\end{tabular}




\section{Table 3(on next page)}

Occurrence of amino acid mutations in neuraminidase in AIVs from Kazakhstan 


\begin{tabular}{|l|l|l|l|}
\hline Amino acid position & Polymorphism & \multicolumn{2}{|l|}{ Allelic frequencies (\%) } \\
\hline 9 & T/A & T (93.8) & $\mathrm{A}(6.3)$ \\
\hline 70 & V/I & $\mathrm{V}(93.8)$ & $\mathrm{I}(6.3)$ \\
\hline 71 & $\mathrm{~V} / \mathrm{I}$ & $\mathrm{V}(87.5)$ & $\mathrm{I}(12.5)$ \\
\hline 72 & $\mathrm{E} / \mathrm{K}$ & $\mathrm{E}(93.8)$ & $\mathrm{K}(6.3)$ \\
\hline 84 & $\mathrm{~N} / \mathrm{S}$ & $\mathrm{N}(93.8)$ & $\mathrm{S}(6.3)$ \\
\hline 88 & $\mathrm{P} / \mathrm{S}$ & $\mathrm{P}(93.8)$ & $\mathrm{S}(6.3)$ \\
\hline 141 & $\mathrm{~K} / \mathrm{R}$ & $\mathrm{K}(75.0)$ & $\mathrm{R}(25.0)$ \\
\hline 175 & $\mathrm{~V} / \mathrm{L}$ & $\mathrm{V}(93.8)$ & $\mathrm{L}(6.3)$ \\
\hline 330 & $\mathrm{Q} / \mathrm{R}$ & $\mathrm{Q}(87.5)$ & $\mathrm{R}(12.5)$ \\
\hline 449 & $\mathrm{D} / \mathrm{E}$ & $\mathrm{D}(87.5)$ & $\mathrm{E}(12.5)$ \\
\hline 466 & $\mathrm{D} / \mathrm{N}$ & $\mathrm{D}(93.8)$ & $\mathrm{N}(6.3)$ \\
\hline 469 & $\mathrm{G} / \mathrm{E}$ & $\mathrm{G}(87.5)$ & $\mathrm{E}(12.5)$ \\
\hline
\end{tabular}

1 


\section{Table 4 (on next page)}

List of amino acid mutations found in neuraminidase in AIVs from Kazakhstan 


\begin{tabular}{|c|c|c|c|c|c|c|c|c|c|c|c|c|}
\hline \multirow[t]{2}{*}{ Name, Accession } & \multicolumn{12}{|c|}{ Position } \\
\hline & 9 & 70 & 71 & 72 & 84 & 88 & 141 & 175 & 330 & 449 & 466 & 469 \\
\hline $\begin{array}{l}\text { A/goose/Kazakhstan/4-190- } \\
\text { 20-B-H5N8-1/2020 } \\
\text { EPI1882526 }\end{array}$ & $\mathrm{T}$ & $\mathrm{V}$ & $\mathrm{V}$ & $\mathrm{E}$ & $\mathrm{S}$ & $\mathrm{P}$ & $\mathrm{K}$ & $\mathrm{V}$ & Q & $\mathrm{D}$ & $\mathrm{D}$ & $\mathrm{G}$ \\
\hline $\begin{array}{l}\text { A/chicken/Kazakhstan/220-B- } \\
\text { 2-H5N8-4/2020 EPI1882546 }\end{array}$ & $\mathrm{T}$ & $\mathrm{V}$ & $\mathrm{V}$ & $\mathrm{E}$ & $\mathrm{S}$ & $\mathrm{P}$ & $\mathrm{K}$ & $\mathrm{V}$ & $\mathrm{Q}$ & $\mathrm{D}$ & $\mathrm{D}$ & $\mathrm{G}$ \\
\hline $\begin{array}{l}\text { A/duck/Kazakhstan/12-20-B- } \\
\text { Talg-11/2020 EPI1882549 }\end{array}$ & $\mathrm{T}$ & $\mathrm{V}$ & $\mathrm{V}$ & $\mathrm{E}$ & $\mathrm{N}$ & $\mathrm{P}$ & $\mathrm{R}$ & V & Q & $\mathrm{D}$ & $\mathrm{D}$ & $\mathrm{G}$ \\
\hline $\begin{array}{l}\text { A/goose/Kazakhstan/7-20-B- } \\
\text { Talg-12/2020 EPI1882550 }\end{array}$ & $\mathrm{T}$ & $\mathrm{V}$ & $\mathrm{V}$ & $\mathrm{E}$ & $\mathrm{N}$ & $\mathrm{P}$ & $\mathrm{R}$ & V & Q & $\mathrm{D}$ & $\mathrm{D}$ & $\mathrm{G}$ \\
\hline $\begin{array}{l}\text { A/swan/Kazakhstan/9-20-B- } \\
\text { Talg-39/2020 EPI1882553 }\end{array}$ & $\mathrm{T}$ & $\mathrm{V}$ & $\mathrm{V}$ & $\mathrm{K}$ & $\mathrm{N}$ & $\mathrm{P}$ & $\mathrm{K}$ & V & Q & $\mathrm{D}$ & $\mathrm{D}$ & $\mathrm{G}$ \\
\hline $\begin{array}{l}\text { A/chicken/Kazakhstan/12-20- } \\
\text { B-Talg-45/2020 EPI1882554 }\end{array}$ & $\mathrm{T}$ & $\mathrm{V}$ & $\mathrm{V}$ & $\mathrm{E}$ & $\mathrm{N}$ & $\mathrm{S}$ & $\mathrm{K}$ & V & Q & $\mathrm{D}$ & $\mathrm{D}$ & $\mathrm{G}$ \\
\hline $\begin{array}{l}\text { A/crow/Kazakhstan/15-20-B- } \\
\text { Talg-4/2020 EPI1882557 }\end{array}$ & $\mathrm{T}$ & $\mathrm{V}$ & $\mathrm{V}$ & $\mathrm{E}$ & $\mathrm{N}$ & $\mathrm{P}$ & $\mathrm{R}$ & V & Q & $\mathrm{D}$ & $\mathrm{D}$ & $\mathrm{G}$ \\
\hline $\begin{array}{l}\text { A/swan/Kazakhstan/1-267- } \\
\text { 20-B-Talg-52/2020 } \\
\text { EPI1882558 }\end{array}$ & $\mathrm{T}$ & $\mathrm{V}$ & I & $\mathrm{E}$ & $\mathrm{N}$ & $\mathrm{P}$ & $\mathrm{K}$ & $\mathrm{V}$ & $\mathrm{R}$ & $\mathrm{D}$ & $\mathrm{D}$ & $\mathrm{E}$ \\
\hline $\begin{array}{l}\text { A/pigeon/Kazakhstan/15-20- } \\
\text { B-Talg-5/2020 EPI1882561 }\end{array}$ & $\mathrm{T}$ & $\mathrm{V}$ & $\mathrm{V}$ & $\mathrm{E}$ & $\mathrm{N}$ & $\mathrm{P}$ & $\mathrm{R}$ & $\mathrm{V}$ & Q & $\mathrm{D}$ & $\mathrm{D}$ & $\mathrm{G}$ \\
\hline $\begin{array}{l}\text { A/chicken/Kazakhstan/1-20- } \\
\text { B-Talg-67/2020 EPI1882562 }\end{array}$ & $\mathrm{T}$ & $\mathrm{V}$ & $\mathrm{V}$ & $\mathrm{E}$ & $\mathrm{N}$ & $\mathrm{P}$ & $\mathrm{K}$ & $\mathrm{V}$ & $Q$ & $\mathrm{D}$ & $\mathrm{D}$ & $\mathrm{G}$ \\
\hline $\begin{array}{l}\text { A/domestic } \\
\text { goose/Kazakhstan/1-248_2- } \\
\text { 20-B/2020 EPI1811603 }\end{array}$ & A & $\mathrm{V}$ & $\mathrm{V}$ & $\mathrm{E}$ & $\mathrm{N}$ & $\mathrm{P}$ & $\mathrm{K}$ & $\mathrm{L}$ & Q & $\mathrm{D}$ & $\mathrm{D}$ & $\mathrm{G}$ \\
\hline $\begin{array}{l}\text { A/chicken/Kazakhstan/Kn- } \\
\text { 3/2020 EPI1839260 }\end{array}$ & $\mathrm{T}$ & V & $\mathrm{V}$ & $\mathrm{E}$ & $\mathrm{N}$ & $\mathrm{P}$ & $\mathrm{K}$ & V & $\mathrm{Q}$ & $\mathrm{E}$ & $\mathrm{D}$ & $\mathrm{G}$ \\
\hline $\begin{array}{l}\text { A/chicken/Kazakhstan/Kn- } \\
\text { 6/2020 EPI1839268 }\end{array}$ & $\mathrm{T}$ & $\mathrm{V}$ & $\mathrm{V}$ & $\mathrm{E}$ & $\mathrm{N}$ & $\mathrm{P}$ & $\mathrm{K}$ & $\mathrm{V}$ & $\mathrm{Q}$ & $\mathrm{E}$ & $\mathrm{D}$ & $\mathrm{G}$ \\
\hline $\begin{array}{l}\text { A/domestic } \\
\text { duck/Kazakhstan/1-274-20- } \\
\text { B/2020 EPI1811613 }\end{array}$ & $\mathrm{T}$ & $\mathrm{V}$ & $\mathrm{V}$ & $\mathrm{E}$ & $\mathrm{N}$ & $\mathrm{P}$ & $\mathrm{K}$ & $\mathrm{V}$ & $\mathrm{Q}$ & $\mathrm{D}$ & $\mathrm{D}$ & $\mathrm{G}$ \\
\hline $\begin{array}{l}\text { A/domestic } \\
\text { goose/Kazakhstan/1-242_2- } \\
\text { 20-B/2020 EPI1811621 }\end{array}$ & $\mathrm{T}$ & $\mathrm{V}$ & $\mathrm{I}$ & $E$ & $\mathrm{~N}$ & $\mathrm{P}$ & $\mathrm{K}$ & $\mathrm{V}$ & $\mathrm{R}$ & $\mathrm{D}$ & $\mathrm{D}$ & $E$ \\
\hline $\begin{array}{l}\text { A/mute swan/Kazakhstan/1- } \\
\text { 267-20-B/2020 EPI1811586 }\end{array}$ & $\mathrm{T}$ & I & V & $\mathrm{E}$ & $\mathrm{N}$ & $\mathrm{P}$ & $\mathrm{K}$ & V & $\mathrm{Q}$ & $\mathrm{D}$ & $\mathrm{N}$ & $\mathrm{G}$ \\
\hline
\end{tabular}


Figure 1

Map of Kazakhstan (with adjacent territories of neighbor countries) showing locations were samples were collected for full-genome sequencing. Source: authors.

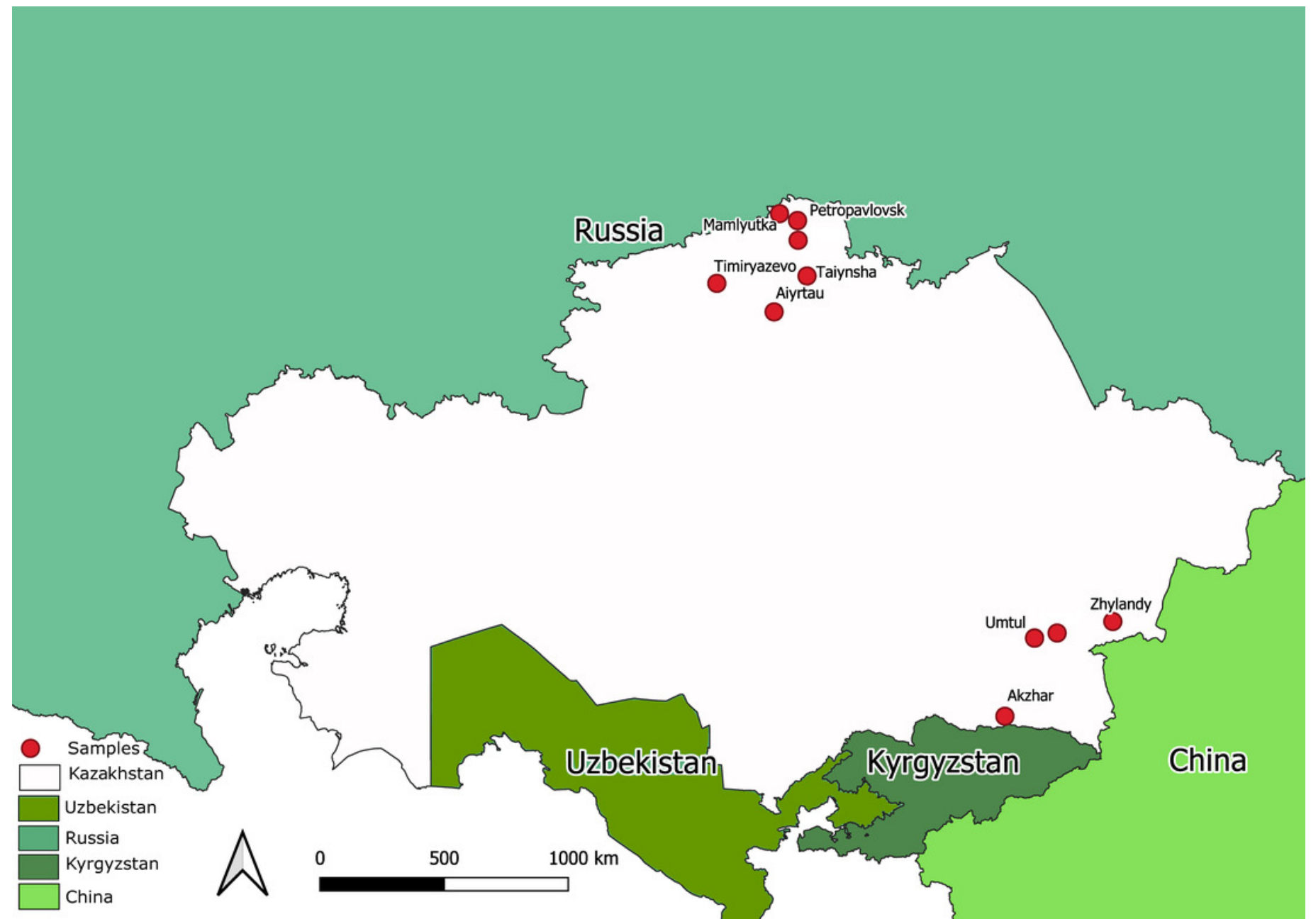




\section{Figure 2}

Phylogenetic tree for the hemagglutinin (HA) gene

The tree is split in two parts, each part in a separate panel. The consensus tree was built using the Bayesian inference as described in the Materials and Methods. Branch tips are labeled with the GISAID isolate name (EPI_ISL), accession number (EPI) and additional markings. Numbers at tree nodes show the statistical support (posterior probability percent). A multiple alignment used to build this tree is provided in the Supplementary Information. Panel a, HPAI A/H5N8 viruses from Kazakhstan year-2020 outbreaks cluster together with contemporary isolates from Eurasia and belong to the $\mathrm{H} 5$ clade 2.3.4.4b. Hemagglutinin clades 2.3.4.4a-2.3.4.4h as well as clades 2.3.4.1-2.3.4.3 (outgroup) are present in the tree. Panel b, expanded look of the collapsed branch from panel a. Viruses from Kazakhstan cluster together with isolates from Russia (Siberia, Urals, Caucasus) and Eastern Europe. Labels: viruses sequenced by our group are labeled with filled circles next to GISAID accession numbers. Isolates sequenced in other laboratories and downloaded from GISAID for this study are labeled with filled squares. Clusters with statistical support $99-100 \%$ are labeled B1-B5 for describing the results. 


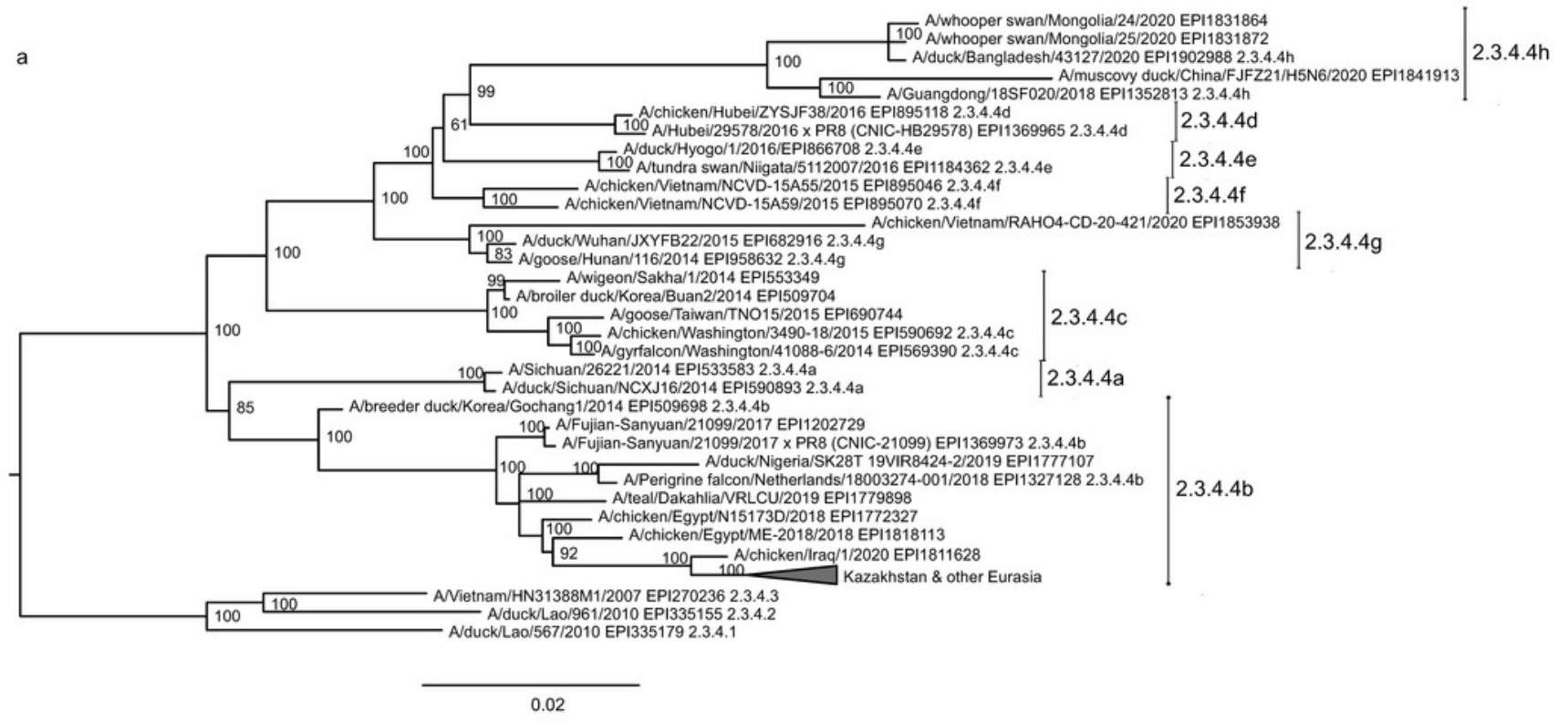

b

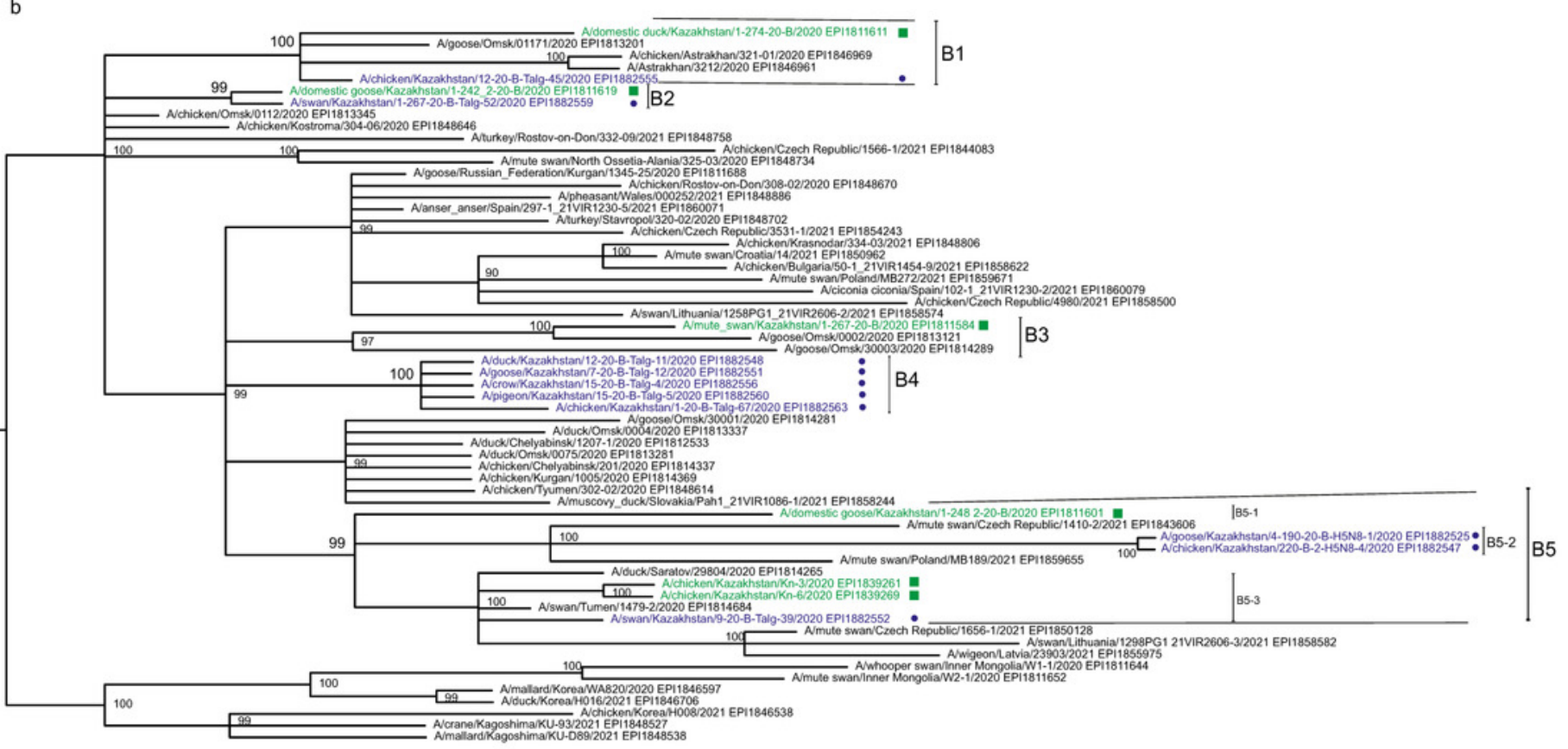

0.001 
Figure 3

Phylogenetic tree for the neuraminidase (NA) gene

The tree was built and labeled similarly to the tree in Fig. 2. A multiple alignment for the NA tree is presented in the Supplementary Information. NA clusters labeled B1-B4 correspond to the eponymous HA clusters in Fig. 2. Members of one HA cluster B5 in the NA tree are present as separate branches B5-1 - B5-3.

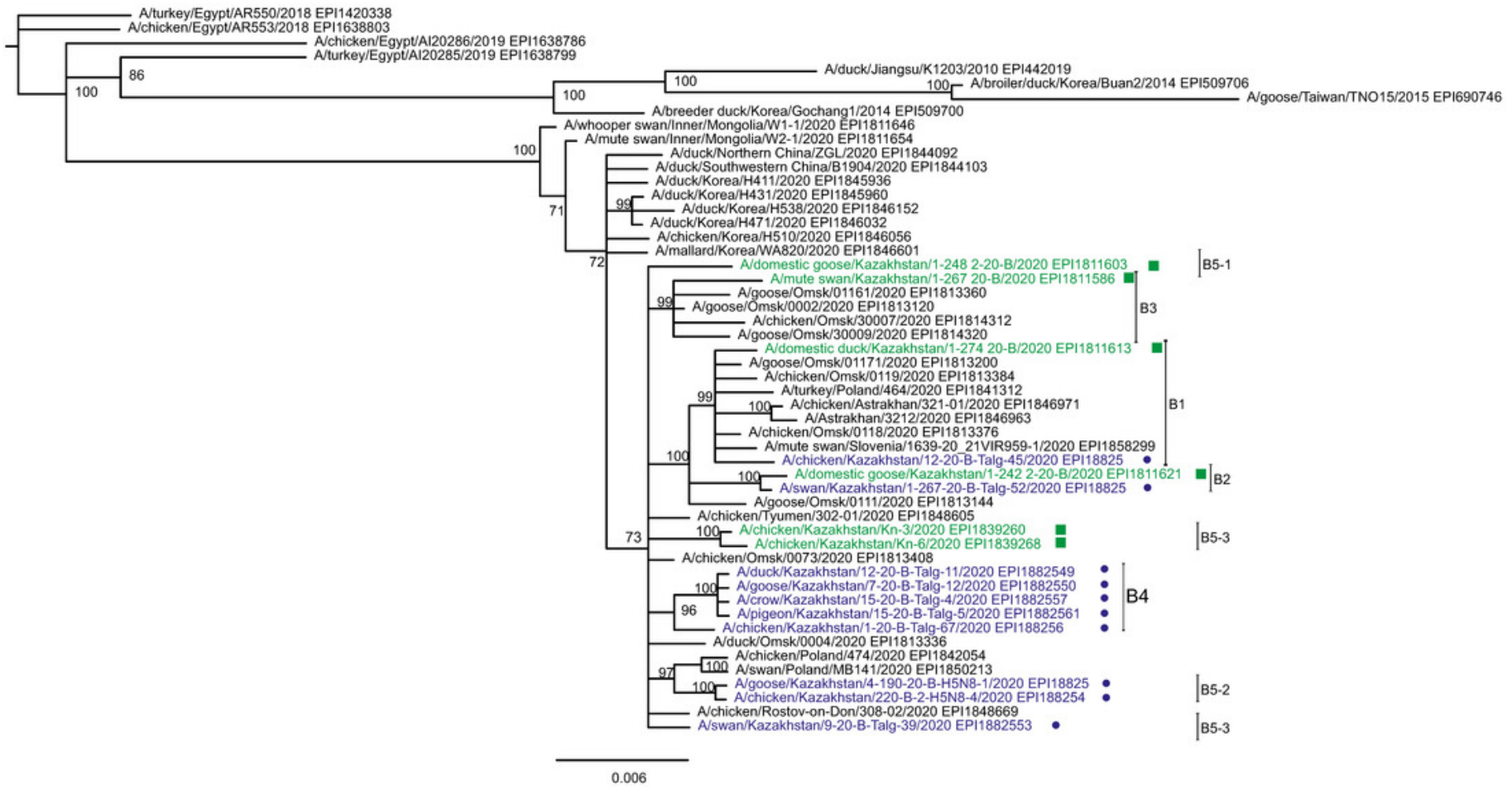

